\title{
Malignant potential of epithelioid angiomyolipomas of the liver: A case report and comprehensive review of the literature
}

\author{
ZOE GAROUFALIA $^{1}$, NIKOLAOS MACHAIRAS ${ }^{1}$, IOANNIS D. KOSTAKIS ${ }^{1}$, ALIKI LIAKEA ${ }^{2}$, \\ PETROS TSAPARAS $^{1}$, GEORGE LIAPIS ${ }^{2}$ and GEORGIOS C. SOTIROPOULOS ${ }^{1}$ \\ ${ }^{1}$ Second Department of Propaedeutic Surgery, Laiko General Hospital; ${ }^{2}$ First Department of Pathology, \\ Medical School, National and Kapodistrian University of Athens, 11527 Athens, Greece
}

Received April 14, 2018; Accepted June 6, 2018

DOI: $10.3892 / \mathrm{mco} .2018 .1659$

\begin{abstract}
Hepatic epithelioid angiomyolipoma (HEAML) is a rare mesenchymal tumor that has been reported to have malignant potential. We herein describe a rare case of atypical HEAML. A 43-year-old Caucasian male patient visited his general practitioner due to a productive cough persisting for $>2$ months. During evaluation with several imaging tests, a chest computed tomography (CT) incidentally revealed a well-demarcated lesion in the caudate lobe of the liver, sized $7 \mathrm{~cm}$. An abdominal magnetic resonance imaging examination confirmed the findings of the CT. The possibility of hepatocellular carcinoma at that time could not be excluded. Due to inconclusive cross-sectional imaging, the patient underwent left hepatectomy with additional resection of segment I. The patient's postoperative course was uneventful. A diagnosis of 'atypical' HEAML was established in the present case. The majority of HEAMLs are considered to be benign, although there are several reported cases exhibiting malignant behavior, such as tumor growth, presence of atypical cells, recurrence after surgical resection, metastasis and invasive growth into the liver parenchyma and alongside the vessels. From 2000 onwards, 19 cases of malignant hepatic AML have been reported. Malignant transformation is considered to occur mostly in the epithelioid subtype. To that end, when epithelioid or atypical characteristics are identified on preoperative biopsy, resection is indicated due to the high probability of malignancy.
\end{abstract}

\section{Introduction}

Angiomyolipomas (AMLs) are rare mesenchymal solid tumors that consist of variable proportions of adipose tissue, smooth muscle cells and blood vessels. In 2002, AMLs were included in perivascular epithelioid cell neoplasms (PEComas) by the

Correspondence to: Dr Zoe Garoufalia, Second Department of Propaedeutic Surgery, Laiko General Hospital, 17 Agiou Thoma Street, 11527 Athens, Greece

E-mail: zoegaroufalia@gmail.com

Key words: liver, epithelioid, angiomyolipoma, atypical, resection
World Health Organization $(1,2)$. According to the dominant cell type, AMLs maybe further divided into epithelioid, spindle-cell and intermediate subtypes. AMLs are usually benign tumors, most often encountered in the kidney, whereas the liver is the most frequent extrarenal site. Extrarenal occurrence of AML is quite uncommon, with $~ 600$ cases of hepatic AMLs reported in the literature to date (3). Hepatic epithelioid AML (HEAML) is a particular type of AML that was first reported by Yamasaki et al in 2000 (4), with no more than 80 cases reported worldwide to date (5). HEAML, which was generally considered to be benign in the past, has malignant potential according to several reports (6). However, the natural history of this type of tumor has not yet been elucidated. There are no pathognomonic clinical, laboratory or radiological characteristics of HEAML; thus, it may easily be mistaken for other types of hepatic tumors, and the rate of misdiagnosis is very high.

A small number of reported cases exhibit malignant characteristics, such as invasive growth pattern, vascular invasion and local recurrence after curative surgical resection, as well as distant metastases. The growth rate and the presence of atypical cells are more critical for estimating the malignant potential of this type of tumor rather than size alone. Early diagnosis of HEAML plays a fundamental role in treatment, which may be challenging due to its atypical characteristics. We herein report the case of an atypical HEAML and conduct a systematic review of the relevant literature.

\section{Case report}

A 43-year-old Caucasian male patient visited his general practitioner due to a productive cough persisting for $>2$ months. Chest X-ray and laboratory tests revealed no specific pathological signs, and the physician suggested a chest computed tomography (CT) scan for further evaluation, which revealed multiple chronic obstructive pulmonary lesions and an incidental liver lesion. More specifically, the CT scan revealed a well-demarcated lesion, $7 \mathrm{~cm}$ in maximum diameter, located in the caudate lobe. The lesion exhibited heterogeneous enhancement following intravenous contrast administration and appeared to compress the intrahepatic portion of the inferior vena cava, without invading it. An abdominal magnetic resonance imaging (MRI) scan confirmed the findings of the CT (Fig. 1A-C). The hepatic lesion exhibited regular borders 


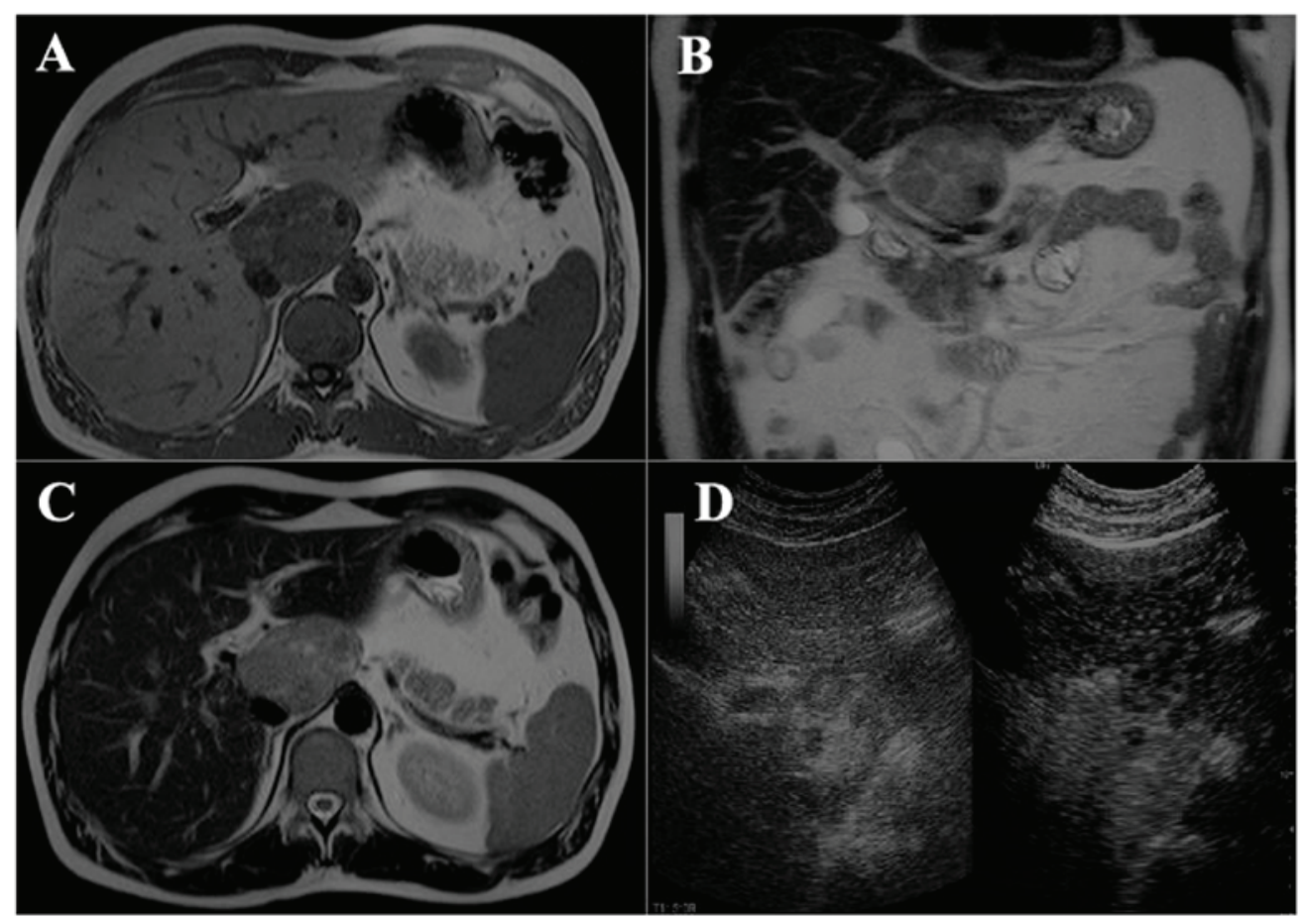

Figure 1. Imaging studies. (A-C) Magnetic resonance imaging of the hepaticlesion. (D) Contrast-enhanced ultrasound of the liver.

with areas of fatty tissue, and demonstrated early washout of the intravenous contrast medium and low attenuation in the portal phase. The possibility of hepatocellular carcinoma (HCC) at that time could not be excluded. Due to inconclusive cross-sectional imaging, a contrast-enhanced ultrasound examination was performed and revealed a hemodynamic behavior mimicking focal nodular hyperplasia (Fig. 1D). Physical examination revealed no abnormalities. Laboratory studies, including $\alpha$-fetoprotein (AFP) and carcinoembryonic antigen (CEA) levels, were within the normal range; the hepatitis virus markers were all negative.

Due to the inability of imaging studies to identify the true nature of the lesion and, more importantly, exclude malignancy, curative resection was performed. The patient underwent left hepatectomy with additional resection of segment I. The postoperative course was uneventful and the patient was discharged on the 7 th postoperative day.

The tumor mainly consisted of two morphologically distinct components. The first component consisted of an admixture of adipocytes, abnormal blood vessels, perivascular epithelioid cells and sheets of foamy cells. These findings were considered to be foci of typical (classical) AML. In abrupt transition with this element, a second component with different morphology was identified. In particular, some tumor areas were composed of sheets of medium- to large-sized cells with epithelioid morphology. In addition, the cells exhibited vesicular nuclei with prominent nucleoli and eosinophilic cytoplasm (epithelioid AML). Focally, cells with bizarre nuclei, multinucleated forms and giant cells were identified. Mitoses were extremely rare. Tumor necrosis or vessel invasion were not detected. Furthermore, areas with cells with 'clear' morphology were identified. The latter areas were diagnosed as 'clear-cell' AML.
Immunohistochemically, the neoplastic cells expressed melanocytic markers, such as melan-A (Dako; Agilent Technologies, Inc., Santa Clara, CA, USA, clone A103, 1:150) and human melanoma black (HMB)-45 (Dako, clone HMB45, 1:150), while HepPar-1 (Dako; Agilent Technologies, Inc., clone OCH1E5, 1:20), S-100 (Thermo Fisher Scientific Inc., Waltham, MA, USA, clone 4C4.9, 1:800) and c-Kit (Dako; Agilent Technologies, Inc., rabbit, 1:600) were negative. The marker of cellular proliferation Ki-67 (Dako; Agilent Technologies, Inc, clone MIB-1, 1:100) was positive in $\sim 5 \%$ of neoplastic cells.

The atypical histological characteristics in the present case included focal cellular pleomorphism, cellular atypia and large tumor size $(>5 \mathrm{~cm})$. The morphological and immunohistochemical findings were consistent with HEAML, including an element of 'typical' AML. No adjuvant treatment was administered postoperatively. The follow-up of the patient included medical history and physical examination every 3 months for the first year initially and every 6 months afterwards, along with abdominal MRI scan at 3, 6, 12 and 24 months. The patient remained asymptomatic and disease-free 2 years following the operation.

\section{Discussion}

In 2002, the World Health Organization recognized PEComas as a different entity, including neoplasms with perivascular epithelioid differentiation. PEComas include AMLs, lymphangioleiomyomatosis and clear-cell 'sugar' tumors (7). EAML is a type of AML composed almost exclusively of epithelioid cells, abnormal blood vessels and few or no adipocytes (8). The clinical characteristics of this type of tumor are usually silent, whereas their natural history has not yet been elucidated. The majority of reported cases 
Table I. Patient characteristics.

\begin{tabular}{|c|c|c|c|c|c|c|c|c|c|}
\hline Authors, year & $\begin{array}{l}\text { Sex/age } \\
\text { (years) }\end{array}$ & $\begin{array}{l}\text { Epithelioid } \\
\text { type }\end{array}$ & Location & $\begin{array}{l}\text { Type of } \\
\text { surgery }\end{array}$ & Metastasis & $\begin{array}{l}\text { Re-op } \\
\text { (yes/no) }\end{array}$ & $\begin{array}{l}\text { Death } \\
\text { (months) }\end{array}$ & $\begin{array}{c}\text { RFS } \\
\text { (months) }\end{array}$ & (Refs.) \\
\hline Liu et al, 2016 & $\mathrm{M} / 34$ & Yes & Left lobe & Left lobectomy & NA & NA & NA & NA & $(5)$ \\
\hline Liu et al, 2016 & $\mathrm{~F} / 31$ & Yes & Right lobe & Right lobectomy & NA & NA & NA & NA & (5) \\
\hline Dalle et al & $\mathrm{F} / 70$ & Yes & Right lobe & $\begin{array}{l}\text { Right } \\
\text { trisegmenectomy }\end{array}$ & Yes (liver) & No & NA & AW & (6) \\
\hline $\begin{array}{l}\text { Mizuguchi } \\
\text { et al, } 2004\end{array}$ & $\mathrm{~F} / 49$ & Yes & Right lobe & $\begin{array}{l}\text { Extended right } \\
\text { trisegmentectomy }\end{array}$ & NA & NA & NA & NA & (26) \\
\hline $\begin{array}{l}\text { Flemming } \\
\text { et al, } 2000\end{array}$ & $\mathrm{~F} / 51$ & Yes & Left lobe & Left lobectomy & No & Yes & No & 36 & (27) \\
\hline $\begin{array}{l}\text { Rouquie } \\
\text { et al, } 2006\end{array}$ & $\mathrm{~F} / 67$ & Yes & Left lobe & Left lobectomy & NA & NA & NA & NA & (28) \\
\hline $\begin{array}{l}\text { Kamimura } \\
\text { et al, } 2010\end{array}$ & $\mathrm{M} / 52$ & Yes & S3-S4 & Left lobectomy & No & No & No & AW & (29) \\
\hline $\begin{array}{l}\text { Fukuda } \\
\text { et al, } 2016\end{array}$ & $\mathrm{M} / 58$ & Yes & S5 & $\begin{array}{l}\text { Anterior } \\
\text { segmentectomy }\end{array}$ & Yes (lungs) & Yes & No & 36 & (30) \\
\hline $\begin{array}{l}\text { Deng } \\
\text { et al, } 2008\end{array}$ & $\mathrm{M} / 30$ & Yes & Right lobe & Right lobectomy & $\begin{array}{l}\text { Yes (pancreas } \\
\text { and lungs) }\end{array}$ & No & Yes (42) & AW & (31) \\
\hline $\begin{array}{l}\text { Parfitt } \\
\text { et al, } 2006\end{array}$ & $\mathrm{~F} / 60$ & Yes & Right lobe & Right lobectomy & $\begin{array}{l}\text { Yes (trapezius } \\
\text { muscle, liver, } \\
\text { lung, pancreas) }\end{array}$ & Yes & No & 108 & (32) \\
\hline Hu et al, 2011 & NA/NA & NA & NA & NA & Yes & No & Yes (14) & AW & (33) \\
\hline $\begin{array}{l}\text { Kobayashi } \\
\text { et al, } 2013\end{array}$ & $\mathrm{~F} / 46$ & No & Right lobe & Right lobectomy & NA & No & No & 5 & (34) \\
\hline $\begin{array}{l}\text { Yang } \\
\text { et al, } 2007\end{array}$ & $\mathrm{~F} / 37$ & NA & Left lobe & $\begin{array}{l}\text { Extended left } \\
\text { lobectomy }\end{array}$ & No & No & Yes (9) & 6 & (35) \\
\hline $\begin{array}{l}\text { Nguyen } \\
\text { et al, } 2008\end{array}$ & $\mathrm{~F} / 43$ & No & Left lobe & $\begin{array}{l}\text { Left lobectomy } \\
\text { and caudate } \\
\text { lobe resection }\end{array}$ & $\begin{array}{l}\text { Yes (peritoneum, } \\
\text { gastrohepaticomentum, } \\
\text { retroperitoneal space) }\end{array}$ & Yes & Yes (8) & 6 & (36) \\
\hline $\begin{array}{l}\text { Croquet } \\
\text { et al, } 2000\end{array}$ & NA/NA & NA & NA & NA & NA & NA & NA & 72 & (37) \\
\hline $\begin{array}{l}\text { Ding } \\
\text { et al, } 2011\end{array}$ & $\mathrm{~F} / 31$ & NA & Right lobe & Right lobectomy & No & No & Yes (7) & 72 & (38) \\
\hline $\begin{array}{l}\text { Wang } \\
\text { et al, } 2015\end{array}$ & $F / 37$ & No & Left lobe & Left lobectomy & Yes (liver) & Yes & NA & NA & (39) \\
\hline Xu et al, 2009 & F/NA & NA & Left lobe & Left lobectomy & Yes & NA & NA & NA & $(40)$ \\
\hline Xu et al, 2009 & NA/NA & NA & NA & NA & Yes & NA & NA & NA & (40) \\
\hline
\end{tabular}

F, female; M, male; NA, information not available; RFS, recurrence-free survival; AW, alive and well.

are incidentally discovered during routine check-ups or while conducting imaging examinations for other conditions. According to previous studies, the majority of the patients are asymptomatic, whereas patients with hepatic AML (HAML) may complain of abdominal discomfort (9-12). Tuberous sclerosis is associated with over half of the cases of renal AML and 5-15\% of the cases of HAML (13). The majority of the patients have no history of liver disease or abnormalities in laboratory tests, and the tumor serum markers, including
CEA, AFP and carbohydrate antigen 19-9, are usually within the normal range.

HAML is a heterogeneous tumor, which makes its distinction from various liver neoplasms based on imaging challenging, despite the advanced techniques currently available. Most HAMLs are misdiagnosed as malignant or focal liver lesions. Accurate diagnosis based on imaging studies alone is rare. On ultrasonography, HAMLs appear as heterogeneously hyperechoic masses. CT and MRI have similar 
diagnostic accuracy rates, and both have a higher diagnostic accuracy compared with ultrasound (14). The presence of fatty areas and solid tissue components is a common presentation of HAML on CT or MRI. However, the presence of adipose tissue is unreliable, since HCCs may also contain fat (9). Other useful imaging characteristics on CT or MRI discriminating between HAML and HCC are the presence of early draining during the portal venous phase, a peripheral rim of decreased enhancement and the absence of a tumor capsule in the hypervascular hepatic tumor $(9,15)$. The CT findings of HEAML, however, are related to the absence of adipose tissue in the lesions. In addition, recognizing imaging characteristics such as lack of a tumor capsule and hypervascularity, with central punctiform or filiform vessels as a characteristic enhancement may help distinguish HEAML from other hepatic tumors (16); however, only $25-52 \%$ of preoperative diagnoses are correct $(17,18)$. Thus, despite the advances in imaging studies, histological diagnosis is necessary for treatment planning.

Differential diagnosis includes high-grade HCC, cholangiocarcinoma and rare sarcomas, such as epithelioid leiomyosarcoma of the liver. The morphological and immunohistochemical findings are usually sufficient for distinguishing these entities. HCC may display clear-cell changes, but immunohistochemically is positive for hepatocyte antigen. Cholangiocarcinoma is an adenocarcinoma and is characterized by the presence of atypical glands and glandular elements. Such neoplastic formations were not found in the present case. Epithelioid leiomyosarcoma may display clear-cell changes, but the tumor cells are negative for melanocytic markers. In the present case, malignant melanoma was excluded due to the lack of S-100 expression. Finally, gastrointestinal stromal tumors usually express the c-Kit marker, which was not observed in our case. Furthermore, the identification of the well-differentiated component of (typical) AML, strongly favors the diagnosis of EAML (19-21).

Atypical characteristics of EAML include a variety of macroscopic and histological findings, such as the size of the tumor $(>5 \mathrm{~cm})$, high mitotic rate, presence of atypical mitotic figures, vascular invasion, necrosis and cellular pleomorphism $(2,7,22,23)$. In the present case, the large size of the tumor, cellular pleomorphism and atypical cells were evident, supporting the diagnosis of 'atypical' EAML.

The majority of HAMLs are considered to be benign, although several cases exhibiting malignant behavior have been reported, including tumor growth, presence of atypical cells, recurrence after surgical resection, metastasis and invasive growth into the liver parenchyma and alongside the vessels (24). Malignant transformation is considered to occur mostly in the epithelioid type (25). The first malignant AML was reported in 2000 by Dalle et al (6). The exact prevalence of malignant AML remains unknown. Most studies state that there have been $\sim 6$ cases of malignant AML reported in the literature to date. To the best of our knowledge, there have been 19 reported cases of malignant AML that are included in this review $(5,6,26-40)$. Since the first case reported by Dalle et al (6), 18 more cases were reported thereafter. As summarized in Table I, 10 of those cases were HEAMLs, and only 3 were typical AMLs. The remaining 6 reported cases of malignant AML do not include an exact description of their cellular components. The recurrence-free survival in those cases ranges from 5 to 108 months. All patients with HEAML underwent surgery. The median age of this population was $\sim 37$ years. The majority of the patients with malignant HEAML were female (6/10). In 6 of the patients with malignant HEAML the mass was located in the right hepatic lobe and in the remaining cases it was in the left hepatic lobe.

A systematic review by Klompenhouwer et al suggested that, when the diagnosis of HAML based on imaging is certain, conservative management is recommended (3). The first surveillance imaging according to this review may be performed 1 year after diagnosis, with biennial follow-up thereafter. However, when the diagnosis is uncertain, biopsy must be performed. If biopsy is inconclusive or shows epithelioid characteristics, resection is indicated. Thus, the presence of epithelioid characteristics in AML is an additional indication for resection.

Although HAMLs were previously considered to be benign, surgeons should be aware of their malignant potential. When the diagnosis is uncertain or when epithelioid or atypical characteristics are found on preoperative biopsy, resection is indicated due to the high probability of malignancy; an aggressive approach contributes to diagnostic accuracy and definitive cure in cases of malignancy.

\section{Acknowledgements}

Not applicable.

Funding

No funding was received.

\section{Availability of data and materials}

Not applicable.

\section{Ethics approval and consent to participate}

Not applicable.

\section{Consent for publication}

Written informed consent was obtained from the patient for the publication of any associated data and accompanying images.

\section{Authors' contributions}

ZG, NM, IDK and PT made substantial contributions to data collection; histopathological analysis and the collection of images were conducted by AL and GL. Literature searching was performed by ZG and PT. ZG, NM, IDK and GCS drafted the manuscript; GCS reviewed the manuscript for intellectually important content. All the authors have read and approved the final version of this manuscript.

\section{Competing interests}

The authors declare that they have no competing interests to disclose. 


\section{References}

1. Fletcher CD, Unni KK and Mertens F (eds): World Health Organization Classification of Tumors of Pathology and Genetics: Tumors of Soft Tissue and Bone. Volume 4. IARC Press, Lyon, France, 2002.

2. Folpe AL and Kwiatkowski DJ: Perivascular epithelioid cell neoplasms: Pathology and pathogenesis. Hum Pathol 41: 1-15, 2010

3. Klompenhouwer AJ, Verver D, Janki S, Bramer WM, Doukas M, Dwarkasing RS, de Man RA and IJzermans JNM: Management of hepatic angiomyolipoma: A systematic review. Liver Int 37 1272-1280, 2017

4. Yamasaki S, Tanaka S, Fujii H, Matsumoto T, Okuda C, Watanabe G and Suda K: Monotypic epithelioid angiomyolipoma of the liver. Histopathol 36: 451-456, 2000.

5. Liu J, Zhang CW, Hong DF, Tao R, Chen Y, Shang MJ and Zhang YH: Primary hepatic epithelioid angiomyolipoma: A malignant potential tumor which should be recognized. World J Gastroenterol 22: 4908-4917, 2016.

6. Dalle I, Sciot R, de Vos R, Aerts R, van Damme B, Desmet V and Roskams T: Malignant angiomyolipoma of the liver: A hitherto unreported variant. Histopathol 36: 443-450, 2000.

7. Hornick JL and Fletcher CD: PEComa: What do we know so far? Histopathol 48: 75-82, 2006.

8. Mai KT, Perkins DG and Collins JP: Epithelioid cell variant of renal angiomyolipoma. Histopathol 28: 277-280, 1996.

9. Cai PQ, Wu YP, Xie CM, Zhang WD, Han R and Wu PH: Hepatic angiomyolipoma: CT and MR imaging findings with clinical-pathologic comparison. Abdom Imaging 38: 482-489, 2013.

10. Nonomura A, Enomoto Y, Takeda M, Takano M, Morita K and KasaiT: Angiomyolipoma of the liver: A reappraisal of morphological features and delineation of new characteristic histological features from the clinicopathological findings of 55 tumours in 47 patients. Histopathol 61: 863-880, 2012.

11. Yang L, Xu Z, Dong R, Fan J, Du Y, Zhang Y, Wang X, Cheng X and Guo J: Is surgery necessary for patients with hepatic angiomyolipoma? Retrospective analysis from eight Chinese cases. J Gastroenterol Hepatol 28: 1648-1653, 2013.

12. Yang X, Li A and Wu M: Hepatic angiomyolipoma: Clinical, imaging and pathological features in 178 cases. Med Oncol 30: 416,2013

13. Tsui WM, Colombari R, Portmann BC, Bonetti F, Thung SN, Ferrell LD, Nakanuma Y, Snover DC, Bioulac-Sage P and Dhillon AP: Hepatic angiomyolipoma: A clinicopathologic study of 30 cases and delineation of unusual morphologic variants. Am J Surg Pathol 23: 34-48, 1999.

14. Yang XY: Hepatic angiomyolipoma: Radiologic-pathologic correlation and clinical features in 178 cases. HPB 15: 104, 2013

15. Wang SY, Kuai XP, Meng XX, Jia NY and Dong H: Comparison of MRI features for the differentiation of hepatic angiomyolipoma from fat-containing hepatocellular carcinoma. Abdom Imaging 39: 323-333, 2014.

16. Ji JS, Lu CY, Wang ZF, Xu M and Song JJ: Epithelioid angiomyolipoma of the liver: CT and MRI features. Abdom Imaging 38 309-314, 2013

17. Krebs S, Esposito I, Lersch C, Gaa J, Schmid RM and Ebert O: Preoperative radiological characterization of hepatic angiomyolipoma using magnetic resonance imaging and contrast-enhanced ultrasonography: A case report. J Med Case Rep 26: 481, 2011.

18. Chang Z, Zhang JM, Ying JQ and Ge YP: Characteristics and treatment strategy of hepatic angiomyolipoma: A series of 94 patients collected from four institutions. J Gastrointestin Liver Dis 20: 65-69, 2011 .

19. Choi WT, Ramachandran R and Kakar S: Immunohistochemical approach for the diagnosis of a liver mass on small biopsy specimens. Hum Pathol 63: 1-13, 2017.

20. Chen ZE and Lin F: Application of immunohistochemistry in gastrointestinal and liver neoplasms: New markers and evolving practice. Arch Pathol Lab Med 139: 14-23, 2015.

21. Geller SA, Dhall D and Alsabeh R: Application of immunohistochemistry to liver and gastrointestinal neoplasms: Liver, stomach, colon, and pancreas. Arch Pathol Lab Med 132: 490-499, 2008.

22. Mete $\mathrm{O}$ and van der Kwast TH: Epithelioid angiomyolipoma: A morphologically distinct variant that mimics a variety of intra-abdominal neoplasms. Arch Pathol Lab Med 135: 665-670, 2011.

23. Folpe AL, Mentzel T, Lehr HA, Fisher C, Balzer BL and Weiss SW: Perivascular epithelioid cell neoplasms of soft tissue and gynecologic origin: A clinicopathologic study of 26 cases and review of the literature. Am J Surg Pathol 29: 1558-1575, 2005.
24. Kamimura K, Nomoto M and Aoyagi Y: Hepatic angiomyolipoma: Diagnostic findings and management. Int J Hepatol 2012: 410781, 2012.

25. Nese N, Martignoni G, Fletcher CD, Gupta R, Pan CC, Kim H, Ro JY, Hwang IS, Sato K, Bonetti F, et al: Pure epithelioid PEComas (so-called epithelioid angiomyolipoma) of the kidney: A clinicopathologic study of 41 cases: Detailed assessment of morphology and risk stratification. Am J Surg Pathol 35: 161-176, 2011.

26. Mizuguchi T, Katsuramaki T, Nobuoka T, Nishikage A, Oshima H, Kawasaki H, Kimura S, Satoh M and Hirata K: Growth of hepatic angiomyolipoma indicating malignant potential. J Gastroenterol Hepatol 19: 1328-1330, 2004.

27. Flemming P, Lehmann U, Becker T, Klempnauer J and Kreipe $\mathrm{H}$ Common and epithelioid variants of hepatic angiomyolipoma exhibit clonal growth and share a distinctive immunophenotype. Hepatology 32: 213-217, 2000.

28. Rouquie D, Eggenspieler P, Algayres JP, Béchade D, Camparo P and Baranger B: Malignant-like angiomyolipoma of the liver: Report of one case and review of the literature. Ann Chir 131: 338-341, 2006 (In French).

29. Kamimura K, Oosaki A, Sugahara S, Mori S, Moroda T, Satoh O, Morita T, Kimura K, Kamura T, Nomoto M and Aoyagi Y: Malignant potential of hepatic angiomyolipoma: Case report and literature review. Clin J Gastroenterol 3: 104-110, 2010.

30. Fukuda Y, Omiya H, Takami K, Mori K, Kodama Y, Mano M, Nomura Y, Akiba J, Yano H, Nakashima O, et al: Malignant hepatic epithelioid angiomyolipoma with recurrence in the lung 7 years after hepatectomy: A case report and literature review. Surg Case Rep 2: 31, 2016.

31. Deng YF, Lin Q, Zhang SH, Ling YM, He JK and Chen XF: Malignant angiomyolipoma in the liver: A case report with pathological and molecular analysis. Pathol Res Pract 204: 911-918, 2008.

32. Parfitt JR, Bella AJ, Izawa JI and Wehrli BM: Malignant neoplasm of perivascular epithelioid cells of the liver. Arch Pathol Lab Med 130: 1219-1222, 2006.

33. Hu WG, Lai EC, Liu H, Li AJ, Zhou WP, Fu SY, Pan ZY, Huang G, Lei Y, Lau WY and Wu MC: Diagnostic difficulties and treatment strategy of hepatic angiomyolipoma. Asian J Surg 34: 158-162, 2011.

34. Kobayashi Y, Kamimura K, Nomoto M, Sugitani S and Aoyagi Y: Immunohistochemical character of hepatic angiomyolipoma: For its management. Case Rep Med 2013: 298143, 2013.

35. Yang CY, Ho MC, Jeng YM, Hu RH, Wu YM and Lee PH: Management of hepatic angiomyolipoma. J Gastrointest Surg 11: 452-457, 2007.

36. Nguyen TT, Gorman B, Shields D and Goodman Z: Malignant hepatic angiomyolipoma: Report of a case and review of literature. Am J Surg Pathol 32: 793-798, 2008.

37. Croquet V, Pilette C, Aubé C, Bouju B, Oberti F, Cervi C, Arnaud JP, Rousselet MC, Boyer J and Calès P: Late recurrence of a hepatic angiomyolipoma. Eur J Gastroenterol Hepatol 12: 579-582, 2000

38. Ding GH, Liu Y, Wu MC, Yang GS, Yang JM and Cong WM: Diagnosis and treatment of hepatic angiomyolipoma. J Surg Oncol 103: 807-812, 2011.

39. Wang WT, Li ZQ, Zhang GH, Guo Y and Teng MJ: Liver transplantation for recurrent posthepatectomy malignant hepatic angiomyolipoma: A case report. World J Gastroenterol 21: 3755-3758, 2015.

40. Xu PJ, Shan Y, Yan FH, Ji Y, Ding Y and Zhou ML: Epithelioid angiomyolipoma of the liver: Cross-sectional imaging findings of 10 immunohistochemically-verified cases. World J Gastroenterol 15: 4576-4581, 2009. 